УДК 618.1

DOI: $10.18101 / 2306-1995-2019-1-44-48$

\title{
АНАЛИЗ СТАТИСТИЧЕСКИХ ДАННЫХ ОНКОЛОГИЧЕСКИХ ЗАБОЛЕВАНИЙ РЕПРОДУКТИВНОЙ СИСТЕМЫ ПО ДАННЫМ ГБУЗ «ГОРОДСКАЯ ПОЛИКЛИНИКА № 1»
}

\section{(C) Ботоева Елена Аполлоновна}

кандидат медицинских наук, доцент, Бурятский государственный университет им. Д. Банзарова Россия, 670002, Улан-Удэ, ул. Октябрьская, 36а

E-mail: elenabotoeva@list.ru

\section{(C) Жовтун Людмила Марковна}

старший преподаватель,

Бурятский государственный университет им. Д. Банзарова Россия, 670002, Улан-Удэ, ул. Октябрьская, 36а

E-mail: elenabotoeva@list.ru

\section{(C) Нечунаева Александра Николаевна}

преподаватель,

Бурятский государственный университет им. Д. Банзарова

Россия, 670002, Улан-Удэ, ул. Октябрьская, 36а

E-mail: alexandra907@mail.ru

\section{(C) Цыжипова Арюна Чимитовна}

врач акушер-гинеколог,

женская консультация ГБУЗ «Городская поликлиника № 1»

E-mail: elenabotoeva@list.ru

\section{(C) Сластина Екатерина Сергеевна}

студент,

Бурятский государственный университет им. Д. Банзарова

Россия, 670002, Улан-Удэ, ул. Октябрьская, 36а

E-mail: elenabotoeva@list.ru

\section{(C) Сунграпова Эржена Даба-Самбуевна}

студент,

Бурятский государственный университет им. Д. Банзарова

Россия, 670002, Улан-Удэ, ул. Октябрьская, 36а

E-mail: elenabotoeva@list.ru

В настоящее время во всем мире продолжает отмечаться рост онкологической заболеваемости, что сопровождается большими физическими, эмоциональными страданиями для больного и для его семьи, а так же становится тяжелым финансовым бременем для системы здравоохранения. Для большинства систем здравоохранения с низким и средним финансированием характерна слабая подготовка в этой области: значительная часть онкологических больных могут получить доступа к своевременной, точной диагностике и лечению рака. Следствием данной ситуации является высокая летальность от онкозаболеваний.

Злокачественные опухоли репродуктивной системы стали одними из главных в структуре онкологической заболеваемости из-за их распространённости среди по- 
$E$. A. Ботоева и дp. Анализ статистических данных онкологических заболеваний репродуктивной системы по данным ГБУЗ «Городская поликлиника № 1»

пуляции и их влияния на психологическую сферу женщины. Вызываемые ими нарушения больше чем другие онкологические заболевания препятствуют нормальной социальной адаптации, а так же вызывают изменения в сексуальной сфере. Ключевые слова: рак, рак шейки матки, рак тела матки, рак яичников.

Для цитирования:

Ботоева Е. А., Жовтун Л. М., Нечунаева А.Н., Цыжипова А.Ч., Сластина Е. С., Сунграпова Э. Д-С. Анализ статистических данных онкологических заболеваний репродуктивной системы по данным ГБУЗ «Городская поликлиника № 1» // Вестник Бурятского государственного университета. Медицина и фармация. 2019. Вып. 1. C. 44-48.

Цели исследования: провести систематический анализ наиболее значимых показателей онкологической статистики для таких локализаций, как злокачественные новообразования органов женской репродуктивной системы.

\section{Задачи:}

1. Изучить литературные источники по данной теме.

2. Изучить статистические данные РФ и ГБУЗ «Городская поликлиника №1»

3. Провести анализ контингента пациентов по нозологиям, стадиям и возрасту, состоящем под диспансерным наблюдением в учреждении наконец отчетного года и наблюдавшихся 5 лет и более. (форма № 7 «Сведения о злокачественных новообразованиях за 2018 г.»)

В Российской Федерации в 2017 году впервые в жизни выявлено 617177 случаев злокачественных новообразований (в том числе 281902 и 335275 у пациентов мужского и женского пола соответственно). Основной объем контингента больных формируется из пациентов со злокачественными новообразованиями молочной железы $(18,4)$, тела матки $(7,1 \%)$, шейки матки $(4,9 \%)$. Среди пула пациентов, наблюдавшихся 5 лет и более, 20,6\% от общего числа занимают пациентки с опухолями молочной железы, $8,2 \%$ - пациентки с опухолями тела матки, $6,0 \%$ - пациентки с раком шейки матки, $3,4 \%$ пациентки с опухолями яичника, и всего $3,0 \%$ занимают случаи новообразований трахеи, бронхов, легкого.

Ведущей онкологической патологией среди женщин остается рак молочной железы - 21,1\%, 14,6\% (с меланомой - 16,6\%) занимают новообразования кожи, далее следуют новообразования тела матки - 7,8\%, ободочной кишки $7,2 \%$, рак шейки матки $-5,3 \%$, желудка $-4,7 \%$, лимфатической и кроветворной ткани $-4,6 \%$.

Из этого следует, что наибольший удельный вес в структуре онкологической заболеваемости женщин имеют злокачественные новообразования органов репродуктивной системы $(39,2 \%)$, при этом опухоли половых органов составляют $18,2 \%$ всех злокачественных новообразований у женщин.

По данным ГБУЗ «Городская поликлиника №1» на 01.01.2019 на «Д» учете со злокачественными опухолями состоит 1592 чел., из них 64,5\% женского пола (1062 чел.), из них на долю ЗНО репродуктивной системы приходится 47,4\%. Структура онкологических заболеваний и распределение по возрасту следующая:

- ЗНО молочной железы - 50,2\% $(38,5 ; 36,5 ; 25,8$ для возраста 60-70 лет, старше 70 и 40-50 лет соответственно)

- ЗНО шейки матки - 29,1\% (29\%, 28\%, 19\% для возрастов 40-50, 50-60 и 60-70 лет соответственно) 
- 3 НО яичника - 10,5\% $\%(32 \%, 24 \%, 15 \%$ для возрастов 60-70, 50-60 и 30-40 лет)

- 3 ЗНО тела матки - 8,9 \% (40\% - 60-70 лет; 28\% старше 70 лет; 24\% 50-60 лет)

- 3 ЗНО вульвы - $0,9 \%$

- ЗНО влагалища - $0,4 \%$

Одним из основных показателей, определяющих прогноз онкологического заболевания, является степень распространенности опухолевого процесса на момент диагностики. В РФ в 2017 г. 29,8\% злокачественных новообразований были диагностированы в I стадии заболевания, 25,8\% во II стадии, 18,8\% в III стадии. Было выявлено 7768 случаев рака в стадии insitu, что соответствует 1,3 случаев на 100 впервые выявленных злокачественных новообразований. В ГП № 1 показатели следующие: диагностированы в I стадии заболевания 26,4 \%, II стадия 48,8\%, III стадия - 22,5\%. Было выявлено 14 случаев insitu: 12 случаев - рак шейки матки, по 1 случаю для рака яичника и рака тела матки. В развитых странах 2/3 новообразований шейки матки выявляются в стадии insitu, в России 1/5.

Одним из основных критериев оценки диагностического компонента помощи онкологическим больным в учреждениях общей лечебной сети административной территории является показатель запущенности. В 2017 г. в России 20,2\% злокачественных новообразований диагностированы при наличии отдаленных метастазов. Для ГБУЗ «Городская поликлиника № 1» наиболее высокий вес опухолей IV степени зафиксирован для ЗНО яичника - 7,6 \%. Недопустимо высокие показатели запущенности отмечены при диагностике новообразований визуальных локализаций. Так, показатели РФ: в поздних стадиях (III-IV) выявлены 32,4\% шейки матки; 29,5\% молочной железы. Для ГБУЗ «Городская поликлиника № 1» отмечается высокий показатель для рака шейки матки - 27,5\%.

Несмотря на рост диагностических возможностей, оснащенности медицинских учреждений высокоэффективным диагностическим оборудованием, развитие новых диагностических методик, доля больных, заболевание у которых выявлено на ранней стадии опухолевого процесса недостаточно высокая, особенно при визуальных опухолях.

Анализируя полученные данные, мы пришли к выводу, что в ГП №1 наибольший показатель в структуре онкозаболеваний приходится на молочной железы и рак шейки матки. Представленные данные подтверждают важность ранней и своевременной диагностики злокачественных новообразований женских половых органов для снижения уровня запущенности и повышения выживаемости онкологических пациенток.

Литература

1. Сайт MАИР [Электронный pecypc]. URL: https://www.iarc.fr (дата обращения: 20.02.2018).

2. The Global Cancer Observatory (включая базуданных GLOBOCAN 2018) [Электронный ресурс]. URL: http://gco.iarc.fr (дата обращения: 03.02.2019).

3. Global Cancer Statistics 2018: GLOBOCAN Estimates of Incidence and Mortality Worldwide for 36 Cancers in 185 Countries. Bray F, et al. CA: A Cancer Journal for Clinicians 2018;0:1-31. URL: https://onlinelibrary.wiley.com/doi/full/10.3322/caac.21492 (дата обращения: 20.02.2018). 
E. А. Ботоева и $\partial$. Анализ статистических данных онкологических заболеваний репродуктивной системы по данным ГБУЗ «Городская поликлиника № 1»

4. Cancer incidence and mortality worldwide: Sources, methods and major patterns in GLOBOCAN 2012. Ferlay J, et al. Int. J. Cancer: 136, E359-E386 (2015). https://onlinelibrary.wiley.com/doi/full/10.1002/ijc.29210 (дата обращения: 20.02.2018).

5. Пресс-релиз [Электронный ресурc]. URL: http://www.iarc.fr/en/mediacentre/pr/2018/pdfs/pr263_E.pdf (дата обращения: 20.02.2018).

6. Злокачественные новообразования в России в 2017 году (заболеваемость и смертность) [Электронный ресурс] / под ред. А. Д. Каприна, В. В. Старинского, Г. В. Петровой. М.: МНИОИ им. П. А. Герцена, 2018. URL: http://www. oncology.ru/service/statistics/malignant_tumors/2017.pdf (дата обращения: 20.02.2018).

7. Состояние онкологической помощи населению России в 2017 году [Электронный ресурс] / под ред. А. Д. Каприна, В. В. Старинского, Г. В. Петровой. М.: МНИОИ им. П. А. Герцена, 2018. URL: http://www.oncology.ru/service/statistics/condition/2017.pdf (дата обращения: 20.02.2018).

\section{STATISTICAL DATA ANALYSIS OF ONCOLOGICAL DISEASES OF THE RE- PRODUCTIVE SYSTEM ACCORDING TO THE DATA OF STATE BUDGETARY HEALTHCARE INSTITUTION "MUNICIPAL POLYCLINIC NO. 1"}

Elena A. Botoeva

Candidate of Medical Sciences, Associate Professor

Dorzhi Banzarov Buryat State University

36a Oktyabrskaya st, Ulan-Ude, 670002, Russia

E-mail: elenabotoeva@list.ru

Lyudmila M. Zhovtun

Senior Lecturer

Dorzhi Banzarov Buryat State University

36a Oktyabrskaya st, Ulan-Ude, 670002, Russia

E-mail: elenabotoeva@list.ru

Alexandra N. Nechunaeva

Teacher

Dorzhi Banzarov Buryat State University

36a Oktyabrskaya st, Ulan-Ude, 670002, Russia

E-mail: alexandra907@mail.ru

Aryuna Ch. Tsyzhipova

Obstetrician-gynecologist of antenatal clinic No. 1

36a Oktyabrskaya st, Ulan-Ude, 670002, Russia

E-mail: elenabotoeva@list.ru

Ekaterina S. Slastina

Student

Dorzhi Banzarov Buryat State University

Medical Institute

36a Oktyabrskaya st, Ulan-Ude, 670002, Russia

E-mail: elenabotoeva@list.ru 
Ergena. D.-S. Sungrapova

Student

Dorzhi Banzarov Buryat State University

Medical Institute

36a Oktyabrskaya st, Ulan-Ude, 670002, Russia

E-mail: elenabotoeva@list.ru

At present, an increase in oncological morbidity is continuing all over the world, which is accompanied by great physical and emotional suffering for the patient and his family, and is also becoming a heavy financial burden for the healthcare system. Most low- and medium-funding healthcare systems are characterized by inadequate training in this area: a significant proportion of cancer patients can get access to timely, accurate cancer diagnosis and treatment. The consequence of this situation is a high mortality rate from cancer.

Malignant tumors of the reproductive system have become one of the main in the structure of cancer incidence due to their prevalence among the population and their influence on the psychological state of women. The violations caused by the state more than other oncological diseases impede normal social adaptation, and also cause changes in the sexual sphere.

Keywords: cancer, cervical cancer, uterine cancer, ovarian cancer. 